\title{
Hortas comunitárias como atividade promotora de saúde: uma experiência em Unidades Básicas de Saúde
}

\author{
Community vegetable gardens as a health promotion activity: \\ an experience in Primary Healthcare Units
}

Christiane Gasparini Araújo Costa ${ }^{1}$

Mariana Tarricone Garcia ${ }^{1}$

Silvana Maria Ribeiro ${ }^{1}$

Marcia Fernanda de Sousa Salandini ${ }^{1}$

Cláudia Maria Bógus ${ }^{1}$

${ }^{1}$ Faculdade de Saúde Pública, Universidade de São Paulo. Av. Dr. Arnaldo 715, Cerqueira César. 01246-904 São Paulo SP Brasil.chris@polis.org.br

\begin{abstract}
Urban and peri-urban agriculture (UPA) is being practiced in different settings, contributing to the improvement of health in communities and healthier environments. In order to identify the meanings and implications of the practice of UPA in Primary Healthcare Units (PHU) as an activity of health promotion (HP), and to what extent its therapeutic dimension characterizes it as an activity aligned with complementary and integrative practices (CIP), a qualitative cross-sectional study was performed in Embu das Artes, State of São Paulo. From the analysis, the following main themes arose: health concept, health outcomes, the return to traditional practices and habits and the reorientation of health services. It was possible to identify the close link between the cultivation of vegetable gardens and HP guidelines and fields of action, such as creating healthier environments, boosting community actions, developing personal skills, stimulating autonomy and empowerment and demands for the reorientation of services. The garden activities, set up in PHU areas, proved to be an implementation strategy of CIP. The conclusion reached is that vegetable gardening activities in community gardens are seen to be health promotion practices that integrate key elements of CIP.
\end{abstract}

Key words Complementary therapies, Health promotion, Gardening, Health services, Public health
Resumo A agricultura urbana e periurbana (AUP) vem sendo praticada em diferentes espaços, contribuindo para a melhoria da saúde nas comunidades e ambientes mais saudáveis. Objetivando identificar significados e repercussões da prática da AUP em Unidades Básicas de Saúde (UBS), enquanto uma atividade de Promoção da Saúde (PS), e em que medida sua dimensão terapêutica a caracteriza como uma atividade alinhada às práticas integrativas e complementares, foi realizado um estudo transversal com abordagem qualitativa no município de Embu das Artes, SP. Da análise, emergiram as seguintes categorias: concepção de saúde, resultados na saúde, resgate de práticas e hábitos tradicionais e reorientação dos serviços de saúde. Identificou-se a estreita ligação entre a prática das hortas e as diretrizes e campos de ação da PS como: criação de ambientes saudáveis, reforço da ação comunitária, desenvolvimento de habilidades pessoais, estímulo à autonomia e empoderamento e demandas por reorientação dos serviços. As atividades de horta instituídas nas UBS se mostraram uma estratégia de implementação das práticas integrativas e complementares (PIC). Conclui-se que as atividades de cultivo nas hortas comunitárias mostram-se como práticas promotoras da saúde que integram elementos fundamentais das PIC.

Palavras-chave Terapias complementares, Promoção da saúde, Jardinagem, Serviços de saúde, Saúde Pública 


\section{Introdução}

O cultivo de alimentos em meio urbano é uma atividade milenar, mas foi na segunda metade da década de 1990 que a chamada agricultura urbana e periurbana (AUP) adquiriu destaque no cenário nacional, afirmando-se como instrumento de integração nos processos de desenvolvimento sustentável das pessoas e do ambiente.

Seu marco conceitual engloba produção, transformação e prestação de serviços, de forma segura, gerando produtos agrícolas de toda espécie e pecuários voltados ao autoconsumo, trocas e doações ou comercialização, (re) aproveitando-se, de forma eficiente e sustentável, recursos e insumos locais (solo, água, resíduos sólidos, mão de obra, saberes, etc. $)^{1}$.

A AUP vem sendo praticada em diferentes espaços: privados, institucionais, locais não construíveis e locais verdes urbanos ${ }^{2}$. Entre as principais contribuições da agricultura urbana estão o fortalecimento da segurança alimentar e nutricional, a melhoria da nutrição e da saúde nas comunidades, além de um ambiente mais saudável ${ }^{3}$.

Mesmo sendo referida em diferentes programas e políticas relacionadas à saúde, a grande maioria dos estudos sobre a AUP enfatiza a dimensão de geração de renda e da produção para o autoconsumo. No entanto, a complexidade do tema possibilita diferentes abordagens de pesquisa, inclusive na área da saúde. Para além da produção de alimentos, o cultivo de plantas medicinais e comestíveis pode agregar dimensões e significados associados à área da saúde, especialmente junto às políticas públicas que têm uma abordagem de assistência integral, tais como a Política Nacional de Promoção da Saúde, a Política Nacional de Práticas Integrativas e Complementares, a Política Nacional de Plantas Medicinais, e a Política Nacional de Educação em Saúde, todas recentemente implementadas, demandando investigações acerca da inserção de tais práticas.

No âmbito do Sistema Único de Saúde (SUS), a perspectiva de Promoção da Saúde (PS) procura desenvolver ações que atuem em aspectos que incidam sobre o processo saúde-doença, incentivando formas mais amplas de intervenção sobre os condicionantes e determinantes sociais de saúde, de forma intersetorial e com participação popular, favorecendo escolhas saudáveis por parte dos indivíduos e coletividades no território onde vivem e trabalham ${ }^{4}$.

Conforme Azevedo et al. ${ }^{5}$, as propostas de ação intersetorial questionam os limites do setor saúde em resolver problemas do binômio saúdedoença, exigindo novas estratégias para seu enfrentamento, que ultrapassam as ações setoriais.

De outro lado, a Política Nacional de Práticas Integrativas e Complementares (PIC) objetiva a incorporação de outras racionalidades terapêuticas, bem como o apoio e a implementação de experiências que já vêm sendo desenvolvidas na rede pública de muitos municípios e estados, dentre as quais se destacam aquelas no âmbito da Medicina Tradicional Chinesa-Acupuntura, da Homeopatia, da Fitoterapia, da Medicina Antroposófica e do Termalismo-Crenoterapia ${ }^{6}$. Dentre as diretrizes definidas para a implementação das PIC no SUS, salienta-se o estímulo à implantação e manutenção de hortos promovidos por órgãos públicos para o fornecimento das plantas e o atendimento da demanda por meio de farmácias públicas de manipulação de fitoterápicos.

$\mathrm{Na}$ América Latina, outros países vêm incorporando as PIC ao sistema oficial de saúde, como o México, onde a homeopatia, a acupuntura e a herbolaria são utilizadas na atenção básica e também na assistência ambulatorial e hospitalar, valorizando a interculturalidade e a abordagem integral da saúde ${ }^{7}$.

No momento atual, em que a efetiva institucionalização das PIC na Rede de Atenção à Saúde ainda carece de diretrizes operacionais para a sua consolidação, a reflexão sobre a implantação de hortas comunitárias e medicinais em Unidades Básicas de Saúde (UBS) pode trazer elementos importantes relacionados às estratégias de implantação de tais ações.

O presente artigo tem por objetivo apresentar os resultados do estudo realizado nas hortas comunitárias e medicinais do Município de Embu das Artes/SP, no que se refere à identificação dos significados e das repercussões desta prática de PS e em que medida a sua dimensão terapêutica a caracteriza como uma atividade alinhada às práticas integrativas e complementares.

\section{Métodos}

Este estudo foi conduzido como parte do projeto "Agricultura Urbana, Promoção da Saúde e Segurança Alimentar e Nutricional no município de Embu das Artes" e obteve aprovação do Comitê de Ética em Pesquisa da Faculdade de Saúde Pública da Universidade de São Paulo.

Para o tratamento desse recorte empírico, valemo-nos da abordagem qualitativa por ser um método que valoriza a dimensão das represen- 
tações feitas pelos sujeitos e, portanto, capaz de permitir a identificação dos significados atribuídos pelos participantes às experiências, relacionando-os ao referencial da Promoção da Saúde, seus campos e princípios ${ }^{8}$.

A pesquisa privilegiou a análise dos depoimentos por considerar que a fala constitui material primordial da investigação qualitativa, sendo capaz de revelar valores, crenças, representações e significados latentes de um determinado grupo 9 .

Dada à natureza dos sujeitos que participaram do projeto, com diferentes graus de inserção na experiência, procurou-se distinguir por dentro das categorias estabelecidas, falas de cunho valorativo, sobre planos mais amplos, como política e financiamento das falas que remetem à dimensão da experiência concreta dos segmentos envolvidos.

Para a produção dos dados analisados neste artigo realizamos visitas de campo, grupos focais (GF) com usuários e técnicos das UBS envolvidos com as hortas comunitárias, entrevistas com as gerentes das mesmas UBS e com informanteschave, representantes de gestores municipais, coordenadores de programas/projetos municipais e do Conselho Municipal de Saúde de Embu das Artes. Todos os GF foram conduzidos pelo mesmo moderador e tiveram a presença de um observador que captava a reação dos participantes e tomava notas durante a condução do GF. Todas as sessões de GF e as entrevistas semiestruturadas foram gravadas e posteriormente transcritas.

Dois GF foram realizados com usuários das UBS, nos meses de maio e outubro de 2013. O GF com técnicos da saúde de nível médio foi realizado no mês de junho de 2013. As oito entrevistas realizadas ocorreram durante os anos de 2012 a 2014, e envolveram gestores públicos, coordenadores de programas/projetos da área de saúde, da Prefeitura de Embu das Artes, e um membro do Conselho Municipal de Saúde.

Foram entrevistados 4 gestores municipais, sendo 3 mulheres e 1 homem, que exerciam as seguintes funções no município: secretária municipal de saúde; coordenadora da área de Promoção da Saúde; coordenadora da área de Educação e Saúde e coordenador da Assistência Farmacêutica.

A organização e processamento dos dados foram realizados com o auxílio do software NVivo10 (QSR InternationalPtyLtd. Version 10, 2012).

A análise do material decorrente das transcrições foi feita em duas etapas: inicialmente cada uma das pesquisadoras, norteadas pelos princípios e campos de ação da PS (concepção de saú- de; reorientação dos serviços de saúde; reforço da ação comunitária; desenvolvimento de habilidades pessoais; autonomia e empoderamento; criação de ambientes favoráveis à saúde) realizou a leitura em profundidade do material e uma pré -análise. Posteriormente, o tratamento dos resultados e a interpretação foram realizados de forma conjunta pelas pesquisadoras.

A análise de conteúdo baseou-se na perspectiva da triangulação de métodos, utilizando-se das informações colhidas em diferentes fontes (entrevistas, GF e anotações de campo), considerando-se a natureza distinta de cada uma das técnicas. $\mathrm{Na}$ análise, procurou-se articular os dados obtidos em campo com os objetivos da pesquisa, na tentativa de interpretar a realidade atribuindo-lhe significados e sentidos até então desconhecidos ${ }^{10}$.

A reflexão científica foi conduzida segundo os parâmetros colocados pela perspectiva dialética que destaca a importância da compreensão do caráter histórico e dinâmico das ações. Ao trabalhar com o conceito de totalidade, esta abordagem abarca não só a descrição das atividades, mas as relações que sustentam a estrutura das ações, seus processos, incluindo o conjunto de representações articuladas pelos atores sociais ${ }^{11}$.

\section{Resultados}

Nos dois GF com usuários das UBS participaram 12 indivíduos, oriundos de 3 UBS, sendo 4 homens e 8 mulheres. A idade média dos participantes era de 63,2 anos (DP $=5,8)$. Apenas um deles havia nascido no município de Embu das Artes e, entre os outros, 5 nasceram em Minas Gerais e 3 em estados da região Nordeste. O tempo médio de residência no município era de 33,8 anos $(\mathrm{DP}=14,6)$. Apenas 1 usuário não possuía experiência com agricultura antes da participação na horta.

O GF com técnicos da saúde de nível médio teve 11 participantes, sendo 9 agentes comunitárias de saúde e 2 auxiliares de enfermagem, todas mulheres e provenientes das 4 UBS que possuíam hortas ativas na época da pesquisa. A idade média das participantes era de 42,0 anos ( $\mathrm{DP}=7,6$ ). Nenhuma delas havia nascido no município de Embu das Artes, sendo que 5 nasceram em municípios do estado de São Paulo, 3 em estados da região Nordeste e 3 no Paraná. O tempo médio de residência no município era de 24,3 anos (DP $=7,3$ ). Apenas 3 profissionais possuíam experiência com agricultura antes da participação na 
horta. Das 11 participantes, 8 também integravam outros grupos de usuários que desenvolviam atividades conjuntas na UBS. As sessões dos GF tiveram em média duas horas de duração.

Das gerentes entrevistadas, a idade média era de 42,4 anos (DP =9,3). Nenhuma delas havia nascido no município de Embu das Artes, sendo que 3 nasceram em municípios do estado de São Paulo e 2 no estado de Pernambuco. O tempo médio de residência no município era de 11,8 anos $(\mathrm{DP}=10,9)$. Das 5 gerentes, 2 possuíam alguma experiência com agricultura antes da participação na horta. As sessões das entrevistas com as gerentes tiveram, em média, 24 minutos de duração.

Da análise, emergiram as seguintes categorias temáticas principais: concepção de saúde, resultados na saúde, resgate de práticas e hábitos tradicionais e reorientação dos serviços de saúde.

\section{Concepção de saúde}

Dentro dessa categoria temática foi possível identificar duas sub categorias mais relevantes: a abordagem holística da saúde e a importância da horta na promoção da saúde. No Quadro 1 aparecem falas ilustrativas desses aspectos que foram coletadas nos registros das entrevistas e dos grupos focais.

\section{Abordagem Holística da Saúde}

As narrativas produzidas tanto pelos técnicos da saúde (técnicos em enfermagem e ACS), como pelos usuários participantes dos GF atestaram mudanças no papel da UBS e resultados positivos advindos da atividade de cultivo de plantas medicinais e alimentares, inclusive demonstrando melhorias na relação interpessoal na UBS.

Em relação à ambiência, as gerentes enfatizaram transformações positivas nos espaços físicos que ficaram mais bonitos, acolhedores e agradáveis após a implantação das hortas, estimulando uma visão positiva de saúde e favorecendo uma nova relação dos usuários com a UBS, sobrepondo-se a uma visão exclusivamente voltada para a doença e entendendo esse como um espaço coletivo e de encontros. A felicidade e o prazer relatados foram associados a sentir-se bem em um local tradicionalmente associado à doença. A sensação de bem-estar foi referida também pelos ACS no GF:

\section{Importância da horta na Promoção da Saúde}

Foram referidos impactos positivos na saúde mental dos envolvidos a partir das atividades de contato com a terra, em espaços participativos e de construção coletiva, os quais propiciam discussões sobre autocuidado, alimentação saudável e o desestímulo ao uso excessivo de medicamentos.

Do ponto de vista dos usuários, fundamentalmente das mulheres, o desfrute de um espaço de encontro e de bem-estar foi acompanhado ainda da conquista em conseguir se organizar e destinar um tempo para si.

Também se explorou a possibilidade de fortalecer o uso de ervas medicinais como forma de redução do uso de medicamentos e aplicação da fitoterapia.

Apesar da relação direta e positiva entre as atividades de horta e aplicação da fitoterapia, as gerentes também apontaram a necessidade de uma maior sensibilização de usuários e técnicos da saúde, bem como a capacitação destes últimos para a introdução dos fitoterápicos na assistência à saúde. Também no GF mencionou-se a necessidade de uma maior sensibilização e conscientização da importância das hortas por parte do conjunto das UBS:

A utilização de alimentos e plantas medicinais colhidos na horta em confraternizações, as oficinas de aproveitamento integral de alimentos e as visitas a outros equipamentos públicos constituíram-se em estratégias positivas de educação alimentar e nutricional para os envolvidos, ampliando a visão sobre a questão alimentar, possibilitando diversidade na escolha de alimentos e favorecendo o consumo de hortaliças inclusive pelos próprios técnicos da saúde.

\section{Resultados na saúde}

No Quadro 2 estão destacados os trechos dos depoimentos que correspondem às subcategorias Desenvolvimento de Habilidades Pessoais, Reforço da Ação Comunitária, Autonomia e Empoderamento que compõem a categoria temática Resultados na Saúde.

\section{Desenvolvimento de Habilidades Pessoais}

O desenvolvimento de diversas habilidades foi mencionado pelas próprias gerentes, principalmente aquelas relacionadas às técnicas de cultivo agroecológico, permacultura, reciclagem e conhecimento de novas espécies de alimentos e plantas. Mesmo os usuários com experiência anterior em cultivo de hortas destacaram no GF o valor das técnicas agroecológicas aprendidas, os benefícios em relação à otimização de recursos e ao combate ao desperdício, propiciados pela prática da compostagem. 
Quadro 1. Falas ilustrativas da categoria Concepção de Saúde e suas subcategorias Abordagem holística da saúde e Importância da horta na promoção da saúde.

\begin{tabular}{|c|c|}
\hline \multicolumn{2}{|r|}{ Categoria: Concepção de Saúde } \\
\hline Subcategoria & Falas \\
\hline $\begin{array}{l}\text { Abordagem holística } \\
\text { da saúde }\end{array}$ & $\begin{array}{l}\text { [...] integrar os pacientes com a unidade, trazer para outra realidade que não só } \\
\text { o atendimento de doenças, mas para atividades de promoção, que têm o intuito } \\
\text { diferente do atendimento médico, de integrá-los e de buscar a saúde, de uma outra } \\
\text { maneira, inclusive pelo conhecimento também de fitoterapia. (Gerente de UBS - } \\
\text { Entrevista) } \\
\text { [...] lá no Santa Emília, os pacientes só iam no posto procurar médico, com a } \\
\text { glicemia, a pressão, totalmente descompensada, e a gente observou que a partir do } \\
\text { momento em que eles começaram a participar da horta e também a fazer caminhada, } \\
\text { isso normalizou e foi diminuindo o numero de medicação e até pararam de ir no } \\
\text { posto só procurar médico [...] (Agente comunitária de saúde - GF) } \\
\text { [...] então a gente adotou uma família dentro do posto, a gente considera como uma } \\
\text { família da gente, muita gente tomava remédio, foram melhorando, tinha diabete alta, } \\
\text { e foi tomando menos medicamento. (Usuária - GF) }\end{array}$ \\
\hline $\begin{array}{l}\text { Importância da horta } \\
\text { na promoção da } \\
\text { saúde }\end{array}$ & $\begin{array}{l}\text { [...] Acho que a horta possibilita trabalhar várias coisas, o próprio esforço físico que } \\
\text { você tem no momento que você está cuidando da horta, já tira você do sedentarismo, } \\
\text { toda semana estar ali mexendo e organizando; o seu envolvimento, o cuidado com } \\
\text { aquilo já é uma atividade de saúde mental porque você se envolve com as plantas, } \\
\text { e, por fim, a questão da alimentação que é superimportante, porque você começa } \\
\text { a resgatar comer sem agrotóxico, comer um alimento natural, saudável. A gente } \\
\text { pode trabalhar a questão da desmedicalização, de tentar evitar o uso abusivo de } \\
\text { medicamentos, usar mais as ervas naturais, então acho que é um projeto que é } \\
\text { estratégico, de autocuidado, dá para você trabalhar um monte de coisas. (Gerente de } \\
\text { UBS - Entrevista) } \\
\text { [...] Minha família gosta que eu participe porque é bom para a nossa mente, } \\
\text { principalmente quando você passa dos } 50 \text {, é muito bom você continuar trabalhando } \\
\text { em alguma coisa, a sua mente se distrai, se você faz uma coisa que gosta, aquele tempo } \\
\text { que eu fico ali com as outras meninas e tiro os matinhos, amontoo lá no canto para } \\
\text { secar tudinho, então para mim é uma coisa legal, maravilhosa, tem dia que eu nem } \\
\text { tomo remédio, esqueço porque eu estou ali preparando, conversando, trocando ideia } \\
\text { e isso é muito bom. (Usuária de UBS - GF) } \\
\text { [...] vejo uma dificuldade também no sentido de ampliar as hortas, é a falta de apoio } \\
\text { das chefias que trabalham nas outras UBS, não é todo mundo que tem esse trabalho } \\
\text { com a promoção de saúde, não foi sensibilizado ainda, não tem a conscientização da } \\
\text { importância, e por isso eu acho que falta esse olhar desse trabalho, um olhar diferente } \\
\text { para que multiplique mais em outras UBS, em outras escolas. (ACS - GF) }\end{array}$ \\
\hline
\end{tabular}

Essas novas habilidades foram também destacadas no GF de técnicos da saúde, propiciando a implantação de hortas em suas casas e mudanças no cuidado com o lixo domiciliar, a exemplo do depoimento de uma das ACS.

\section{Reforço da Ação Comunitária}

A horta foi referida como uma atividade terapêutica da UBS, necessária inclusive pela ausência de outras opções de atividades comunitárias nos seus entornos. Depoimentos apontaram as diversas formas de agenciamentos coletivos propiciados pela participação na horta, como por exemplo, a formação de redes de apoio para o fornecimento de materiais (ferramentas e insumos), restos de alimentos para a compostagem, adubo, sementes e mudas.

No discurso produzido foram ressaltados o companheirismo e as amizades como algo que veio agregar tanto no âmbito profissional como 


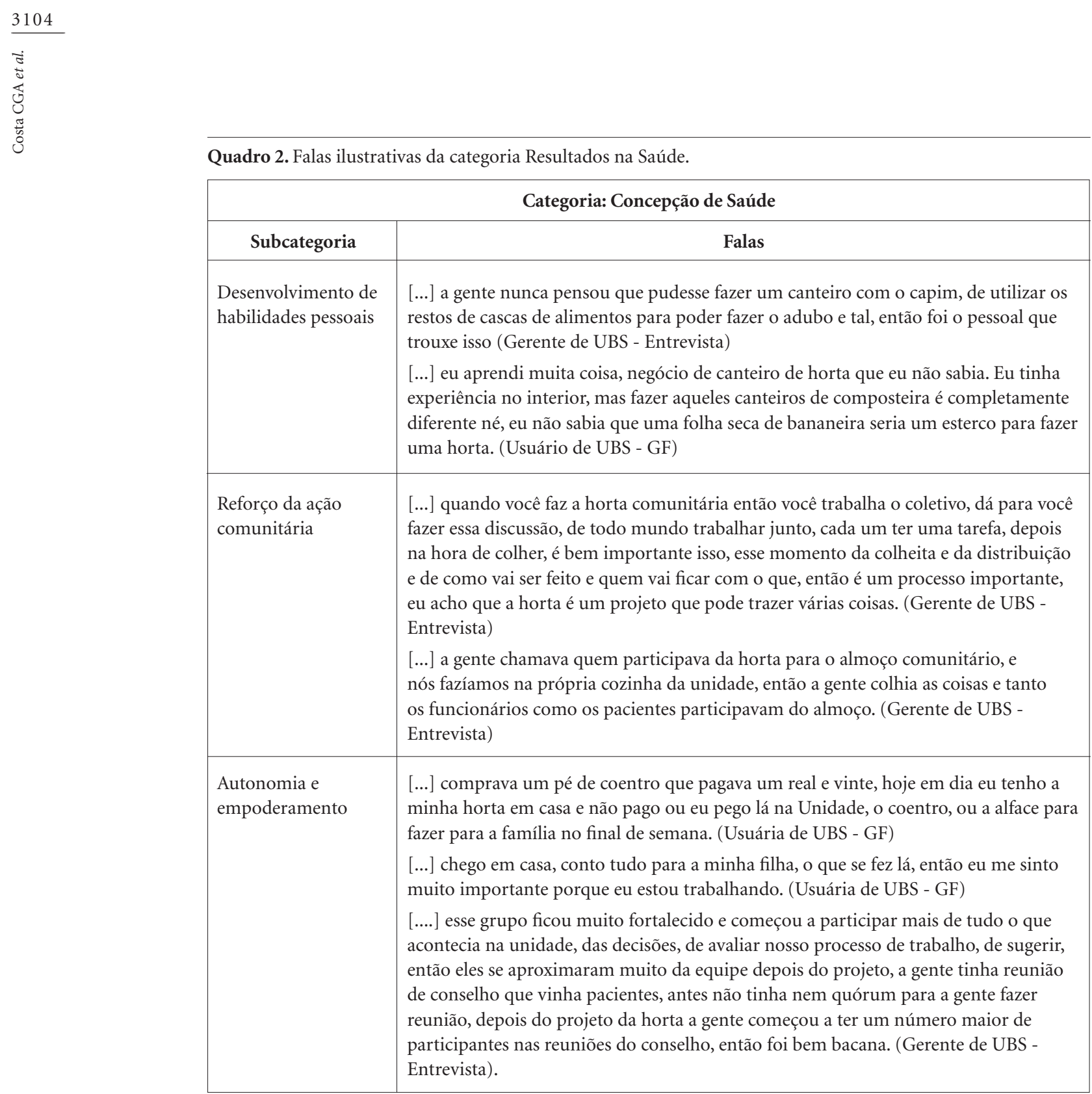

no pessoal. O desenvolvimento do trabalho coletivo nas hortas levou a uma maior união do grupo e a realização de refeições coletivas e visitas a outras hortas auxiliaram na realização das atividades e mutirões.

\section{Autonomia e empoderamento}

O cultivo de alimentos como uma forma, ainda que parcial, de descomprimir o orçamento doméstico foi destacado como uma habilidade e também como uma perspectiva de maior autonomia em relação ao mercado.

Além da participação em um espaço saudável de bem-estar, o tempo dedicado à horta foi percebido pelos usuários como útil e prático, por ter propiciado maior conscientização e aprendizado de ferramentas concretas de cuidados com a própria saúde, estendendo-se aos familiares, vizinhança e meio ambiente em que viviam.

A adesão mais espontânea veio por parte dos idosos e daqueles que tiveram um histórico de trabalho na agricultura.

O sentimento de pertencimento e a maior integração dos pacientes com a UBS, advindos do envolvimento com a horta, determinaram a ampliação da participação também nos conselhos gestores, demonstrando disposição do usuário em se comprometer com as decisões que envolvem o equipamento de saúde como um todo. 

consumiam. Memórias que haviam ficado adormecidas com a vinda para a cidade e com os novos ofícios. Entretanto, foi destacado que, além do resgate de conhecimentos, houve também o aprendizado de novas técnicas, como a compostagem, o uso de resíduos recicláveis, etc.

\section{Reorientação dos serviços de saúde}

A categoria temática Reorientação dos Serviços de Saúde sobressaiu-se em relação às outras e são várias as falas ilustrativas apresentadas no Quadro 4.

Os gerentes das UBS tinham em vista, inicialmente, uma integração do projeto de implantação das hortas com outras atividades de promoção da saúde, o que seria capaz de produzir reorientações nos serviços de saúde. A despeito de tal resultado não ser alcançado em sua totalidade, estes gestores declararam ter conseguido avanços importantes como a utilização da UBS pelos usuários para outras finalidades, incluindo atividades prazerosas e voluntárias.

Diversas dificuldades surgiram para a reorientação do serviço de saúde, das quais foram destacadas: falta de sensibilização dos médicos para que recomendassem aos seus pacientes a participação nas atividades; adesão de outros técnicos e profissionais da saúde da UBS; restrição na variedade de ervas plantadas na horta, falta de capacitação dos técnicos da saúde em fitoterapia.

Segundo depoimentos das gerentes entrevistadas, a atividade da horta não constituiu fator suficiente para ser incorporada por médicos e também por uma maioria de usuários. Ainda assim, é fundamental considerar que a iniciativa colaborou na promoção de uma concepção holística de saúde e de integralidade na atenção à saúde, fomentando novas relações entre usuários e técnicos da saúde.

As gerentes ressaltaram a importância de se incorporar a noção de processo e educação permanente junto aos profissionais de saúde e também usuários, a fim de mudar a prática predominante que privilegia e credita ao médico e aos medicamentos a responsabilidade de resolução dos problemas de saúde.

Para as gerentes, a participação de outros técnicos da saúde sempre foi difícil, houve tentativas com psicólogos e médicos, mas sem sucesso. Quem realmente se envolveu com as hortas foi, em sua maioria, os agentes comunitários da saúde e os auxiliares e técnicos de enfermagem.

Sob a ótica dos agentes comunitários, uma questão apontada no GF foi a falta de uma normatização da atividade, implicando muitas vezes em sobrecarga de trabalho.

Como atividade de natureza multisetorial, a participação dos técnicos da ONG local, a interação com as escolas e a parceria com a assessoria técnica da Secretaria de Meio Ambiente, inclusive no fornecimento de insumos e ferramentas, foi enfatizada nos depoimentos como fundamental e sua interrupção implicou numa diminuição da participação em algumas unidades.

A necessidade de se ampliar os recursos para as atividades de promoção da saúde e, especificamente, para a manutenção das hortas, aliada à necessidade de disponibilizar assistência técnica, foram aspectos bastante destacados pelas gerentes como fundamentais para a continuidade do

Quadro 3. Falas ilustrativas da categoria Resgate de Práticas e Hábitos Tradicionais.

Resgate de práticas e hábitos tradicionais
[...] são pessoas que antes moravam em lugares que tinha terra, que se podia plantar, e que aí veio para a cidade e a cidade foi tomando conta e não tem mais e elas ficavam muito felizes de estarem ali de novo mexendo na terra. (Gerente de UBS - Entrevista)

[...] gosto muito de ficar lá, me sinto super bem, do que acontece, eu fui nascido e criado na roça e, eu vim para São Paulo e me afastei de roça, mas agora voltei a mexer com aterra que é muito bom. (Usuário de UBS - GF)

[...] fui nascido e criado na roça, a gente tinha sempre aquela saudade de mexer com a terra, plantar alguma coisa. (Usuário de UBS - GF) 
Quadro 4. Falas ilustrativas da categoria Reorientação dos Serviços de Saúde.

\section{Categoria: Reorientação dos Serviços de Saúde}

[...] a relação paciente e funcionário é uma relação sempre muito conflituosa, onde o paciente não sente a unidade como se fosse dele, então ele vem só para passar na unidade e pegar remédio e, a partir da horta isso mudou, essa dinâmica do relacionamento da equipe da unidade com a comunidade melhorou muito. (Gerente de UBS - Entrevista)

[...] parece que é fácil: Ah! Vamos fazer Lian Gong, não é isso porque na promoção de saúde você tem essa lógica de desmedicalizar, deshospitalizar, só que não é fácil porque a sociedade não está criada para isso, ela está criada para você vender remédio, para você vender a doença [...] se nós vamos em quatro anos de gestão conseguir aquele objetivo (...) claro que a gente não conseguiu mudar os grandes paradigmas, continua o remédio, continua centrado no médico, continua aquela coisa de pronto socorro, mas eu acho que nós estamos na caminhada certa. (Secretária de Saúde - Entrevista)

[...] o meu serviço era fazer minhas fichas, correr para a rua e trazer o paciente para cá, agora não, eu tenho que me programar para que isso não afete a minha visita lá fora, me programar para trabalhar na horta e não sobrecarregar. (ACS - Entrevista)

[...] por mais que a gente envolva os profissionais, eles precisam de um auxílio, ninguém nunca teve grandes conhecimentos, então precisa ter um apoio, incentivo. (Gerente de UBS - Entrevista)

[...] na questão de fitoterapia a gente está recebendo a visita de uma empresa que está divulgando esse trabalho com os médicos também, uma capacitação, ela está visitando as unidades, orientando as fórmulas que tem disponíveis, as plantas, e deixando o caminho livre assim para ter um acesso dos médicos a essa empresa para ter maiores orientações. (Gerente de UBS - Entrevista)

[...] tem que ser melhor planejado esses projetos, e tem que ser uma coisa que não só a unidade abrace, mas o município abrace como proposta e isso tem que ser intersetorial, não dá para ficar só na saúde. (Gerente de UBS - Entrevista)

[...] quando se pensa nos projetos de promoção, são sempre as agentes que estão envolvidas, é difícil envolver os demais profissionais efetivamente nesses projetos e uma coisa que eu sempre penso é como a promoção fica em segundo plano, precisa acreditar muito, porque todos os nossos projetos são assim, a gente nunca tem verba para as atividades. (Gerente de UBS - Entrevista)

projeto, revelando que a autonomia do grupo não excluiu a importância do técnico e da garantia do recurso financeiro.

A falta de recursos públicos para a manutenção da atividade determinou a criação de diversas formas de mobilização, baseadas no trabalho voluntário de usuários e funcionários para garantir a continuidade das atividades. Por meio de bazares, doações e mutirões, os participantes encontraram formas de suprir as demandas do projeto como a compra de mudas e equipamentos.

A necessidade de maior capacitação dos funcionários das UBS para os cuidados com a horta foi mencionada como um desafio, inclusive como um meio para propor a discussão de temas de educação em saúde, a partir das dinâmicas, divergências e conflitos de grupo que emergem no cotidiano do trabalho na horta.

Diante da indefinição de atribuições e de recursos para o desenvolvimento de ações educativas, uma opção mencionada por gerentes de UBS foi terceirizar a tarefa educativa às empresas de fitoterápicos.

A ausência de uma melhor definição quanto à forma de implantação das plantas medicinais nas UBS foi apontada pelas gerentes como um aspecto limitante e, ao mesmo tempo, defenderam que essa implantação fosse assumida mais efetivamente, intra e intersetorialmente no nível da gestão municipal.

\section{Discussão}

Os GF permitiram a interação entre os participantes envolvidos no contexto investigado, sendo possível que explorassem seus pontos de vista, a partir de reflexões coletivas sobre o envolvimento com as hortas, buscando respostas pertinentes à questão investigada. As entrevistas tiveram a função de complementar as informações e percepções obtidas por meio das observações das 
pesquisadoras, além de contribuir para o aprofundamento de questões que surgiram ao longo das visitas de campo.

Com a análise dos dados foi possível identificar a estreita ligação entre a prática das hortas e as diretrizes da PS, bem como os aspectos, significados e valores associados aos seus diferentes campos e princípios, como a criação de ambientes saudáveis, o reforço da ação comunitária, o desenvolvimento de habilidades pessoais, o estímulo à autonomia e ao empoderamento, o resgate de práticas e hábitos tradicionais e demandas por reorientação dos serviços.

Os resultados explicitaram a horta como um lugar de encontro e, por meio dela, a inauguração de uma nova relação com a UBS. O envolvimento dos participantes permitiu a ampliação da interação dos usuários entre si e com os profissionais de saúde e técnicos, constituindo-se em grupos de apoio e partilha, trocas de saberes e resgate de memórias da infância. Como consequência, identificou-se a elevação da autoestima e do autocuidado, um maior entusiasmo pela participação, relatos sobre a melhora das condições de saúde dos participantes, a revisão de valores em relação à alimentação, a aquisição de uma nova visão da saúde, o empoderamento individual e coletivo e o aprendizado de habilidades com viabilidade de aplicação em outros contextos, como o familiar e a vizinhança.

A partir destes resultados foi possível relacionar as atividades de horta instituídas nos espaços das UBS como uma estratégia de implementação das PIC, por se caracterizar como uma prática complementar às biomédicas tradicionais e integrativa por serem modelos eficazes que privilegiam técnicas naturais, incentivando o uso de fitoterápicos, promovendo maior autonomia, participação social e bem-estar físico e mental dos indivíduos ${ }^{12}$.

Ainda que não constitua um sistema no âmbito de outra racionalidade terapêutica, a prática das hortas mostrou-se uma estratégia complementar ao tratamento de doenças crônicas, alinhada às diretrizes da Política Nacional de Práticas Integrativas e Complementares, que buscam combinar aspectos de sistemas antigos de cura com a biomedicina moderna; a valorização do relacionamento médico-paciente e da comunicação; a consideração da pessoa de forma integral; a utilização de evidências e o enfoque na saúde, na cura e na prevenção de doenças ${ }^{13}$.

As dificuldades apontadas demonstram que, para além da insuficiência de recursos e qualificação profissional, há desafios na integração en- tre a abordagem compreensiva das PIC e a visão biomédica, por representarem paradigmas distintos de racionalidades médicas, que se desdobram em diferentes formas de procedimentos e tratamentos.

Tesser $^{14}$ destaca as contribuições do campo das práticas complementares em saúde-doença para a promoção da saúde no ambiente do SUS. Várias práticas complementares e seus praticantes portam saberes/técnicas especificamente voltados à PS, porém a exploração acadêmica tem repercutido pouco sobre a saúde coletiva e o SUS, a ponto de apenas em 2006 ter havido uma política nacional a respeito, tornando relevante a reflexão sobre as convergências e imbricações, teóricas e práticas, entre o campo das PIC e a promoção da saúde. Contribuir para o reconhecimento, compreensão e exploração dessas imbricações seria o fio condutor desta reflexão, pois segundo o autor:

[...] é comum que essas racionalidades ofereçam práticas, valores e técnicas de promoção de saúde que se realizam também coletivamente em pequenos grupos e valorizam e fomentam a solidariedade, a troca entre os praticantes, o empowerment comunitário. As meditações, as massagens e automassagens, os exercícios psicofísicos ou energéticos, se bem que voltados para o indivíduo, mostram repercussões positivas na sociabilidade, na construção de redes de apoio social, na discussão da participação social e política. Não é por acaso que profissionais do SUS envolvidos com atividades coletivas de tipos variados, inclusive usando técnicas complementares, não raro testemunham que os grupos costumam fomentar cidadãos mais atuantes e mesmo conselheiros locais de saúde. Portanto, é no pólo individual e grupal, numa perspectiva relacional microssocial, que as práticas complementares podem contribuir para a promoção da saúde ${ }^{14}$.

Conforme Souza e Luz $^{15}$ a emergência das novas práticas terapêuticas evidenciam as lacunas da abordagem biomédica da saúde, modelo hegemônico nas ciências, estabelecido a partir da segunda metade do século XIX, tais como a incapacidade de atender à totalidade das demandas das populações, de conter a influência negativa do desenvolvimento do capitalismo na saúde das populações, de lidar com o alívio do sofrimento.

Diferentemente da perspectiva biomédica, que valoriza o diagnóstico e a medicalização, as práticas integrativas enfatizam a dimensão terapêutica, promovendo a autonomia, o autocuidado e a saúde com foco no sujeito e não nas patologias desenvolvidas.

Tesser ${ }^{14}$, em seu estudo de revisão do processo de implantação das PIC, ressalta os méritos das 
práticas complementares, que "estão obtendo reconhecimento da população, da sociedade formal e, em parte, da ciência biomédica; particularmente quanto à experiência com o processo adoecimento-cuidado-cura e quanto ao estímulo do potencial de reequilíbrio e cura do próprio paciente"14.

Ainda que o fomento à pesquisa sobre as práticas integrativas e complementares seja fundamental, há uma série de estudos realizados nos últimos anos com avaliações bastante consistentes sobre a repercussão das PIC na Promoção da Saúde. Um exemplo é a revisão bibliográfica sobre a prática integrativa do Yoga, no período de 1999 a 2007, onde 70\% dos estudos identificados apontou a prática como uma ferramenta útil e promissora para o alívio da dor e do estresse, colaborando também na elevação da autoestima, no favorecimento do autocuidado, na promoção da saúde, melhora da qualidade de vida e na cura ${ }^{16}$. Barros et al. ${ }^{17}$ entrevistaram participantes de um programa de 5 meses de aulas de Hatha Yoga duas vezes por semana para doentes, funcionários e alunos de uma universidade pública de Campinas/SP. Foram observadas melhoras expressivas para alguns participantes em relação aos sintomas que os incomodavam, como ansiedade, dor de cabeça, lombalgia e dor de estômago, e à sensação de bem-estar.

Também Silva e Tesser ${ }^{18}$, ao estudarem a prática da acupuntura em pacientes atendidos pelo SUS, destacam a aceitação e valorização crescente das terapias integrativas e complementares não só por suas virtudes de tratamento e estímulo à autocura, mas também como um meio de "redução de danos", dada a excessiva medicalização vigente atualmente, sobretudo nos casos de dor crônica. No mesmo sentido, Cintra e Figueiredo ${ }^{19}$ encontraram mudanças importantes atribuídas pelos profissionais e usuários ao tratamento com acupuntura em UBS de São Paulo/SP. Destacase a mudança na racionalidade médica para uma visão mais "holística"; mudanças no cotidiano como disciplina, estado emocional, comportamento, atividade física e alimentação; melhora ou extinção de enfermidades como hipertensão, diabetes, doenças osteomusculares, entre outras; e instrumentalização do paciente para o autocuidado, incentivando uma postura ativa e uma visão crítica sobre seu próprio corpo.

Mesmo que a insatisfação com o modelo biomédico possa ser um aspecto que alavanque as PIC e, ainda que o crescimento epidêmico das doenças crônicas não transmissíveis justifique a ênfase na educação em saúde, recuperar a perspectiva potencializadora de autonomia e de auto- cuidado constitui um dos desafios identificados na experiência em estudo.

Para Vaghetti et al. ${ }^{20}$, os cuidados de manutenção da vida e os cuidados curativos surgidos a partir de experiências concretas foram substituídos pelos cuidados médicos, reconhecidos como os únicos científicos. Com a aceleração do tempo, o campo espacial dos cuidados restringiu-se ainda mais, resultando no desaparecimento ou na negação dos laços entre o homem e seu ambiente, seu grupo social, seu universo.

Em Valla et al. ${ }^{21}$, o sentido do cuidar é manifestado em uma visão mais integral, onde não se trata da cura de uma doença, mas da reconstituição ou da produção de um estado físico, mental, emocional, o que está ligado às condições gerais de saúde e envolve determinada capacidade de enfrentamento de situações diversas de exigência física, mental e emocional por parte dos indivíduos, incluindo, nesta situação, os próprios estados de adoecimento.

A natureza do diálogo que vem ocorrendo entre diferentes racionalidades médicas no sistema de saúde é complexa e contraditória, sendo considerada por alguns autores como uma segunda ruptura epistemológica, no sentido de recuperar tradições e o conhecimento popular para o campo da Promoção da Saúde ${ }^{22}$.

Os limites e as potencialidades encontradas constituem subsídios para a formulação de diretrizes para a legitimação institucional da prática das hortas, alinhadas aos valores da PS, com base na reflexão produzida por gestores e usuários participantes do estudo, onde se destacam as questões associadas à metodologia e à forma de implantação.

Cabe perguntar como se dará a implantação da política de plantas medicinais e de fitoterápicos nas UBS: impulsionando processos participativos ou apenas apresentando novos produtos? Os processos de implantação vêm fortalecer quais atores e que relações sociais?

Se a perspectiva da racionalidade biomédica produziu o atendimento clínico, comumente descontextualizado ou fragmentado, que tipo de agenciamento será feito por meio da implantação das PIC? Diferentes concepções engendram formas distintas de implantação.

Outro aspecto fundamental é a intersetorialidade, presente no escopo das políticas humanizadoras. Tais atividades precisam contar com estratégias de natureza intersetorial para viabilizar uma maior integração das ações da saúde e de outras secretarias, realizadas nos equipamentos de saúde ou fora deles. 
O que se vislumbra a partir dos resultados analisados é a necessidade de aprofundar a definição de estratégias intra e intersetoriais, no nível de implantação municipal e gestão de projetos, coerente com a visão holística que os caracterizam.

Para Azevedo et al. ${ }^{5}$, a perspectiva de atuações inter e intrassetoriais no campo das políticas de saúde tende a crescer, diante do acúmulo de discussão já existente que envolve a ampla causalidade do processo saúde-doença. Assim, a abordagem intersetorial torna-se um objetivo a ser alcançado por todas as políticas públicas que têm como diretriz a promoção da qualidade de vida das populações, em uma perspectiva ampliada do conceito de saúde.

Vale lembrar, que a oitava Conferência Global sobre Promoção de Saúde, realizada em Helsinque, Finlândia, em junho de 2013, convocada pela Organização Mundial da Saúde ${ }^{23}$, pautou o tema "Saúde em Todas as Políticas" e, segundo o documento final, trata-se de uma abordagem a ser adotada por gestores de todo o mundo. Saúde em Todas as Políticas é uma abordagem que advoga em nome de políticas públicas de diferentes setores que levem em conta e contemplem as repercussões decorrentes no campo da saúde de forma sistemática na busca de sinergias e efeitos prejudiciais na saúde, a fim de melhorar a saúde da população e os níveis de equidade em saúde. Esta abordagem, fundada sobre os direitos e obrigações relacionados com a saúde, enfatiza as consequências das políticas públicas sobre os determinantes da saúde e tem como objetivo melhorar a responsabilização dos formuladores de políticas para os impactos na saúde no processo de decisão política em todos os níveis ${ }^{23}$.

\section{Conclusão}

Na medida em que promovem a melhoria da saúde e a qualidade de vida, o fortalecimento da prática do cultivo de hortas nas UBS, em bases agroecológicas, pode ser um elemento fundamental, agregando resultados ao objetivo colocado pela Portaria $n^{\circ} 483$, de $1^{\circ}$ de abril de 2014 , que redefine a Rede de Atenção à Saúde das Pessoas com DCNT, de promover hábitos de vida saudáveis com relação à alimentação e à atividade física, como ações de prevenção às doenças crônicas ${ }^{24}$.

É importante valorizar, no campo da alimentação, o papel específico da agricultura urbana como uma atividade que colabora na prevenção de doenças e na PS, favorecendo a participação popular e a difusão de conhecimentos tradicionais.

A disposição da gestão municipal em priorizar as ações da PS e, de outro lado, a receptividade por parte dos usuários em aderir às práticas de cultivo, não foram fatores suficientes para o fortalecimento dos projetos nas UBS.

A questão dos recursos financeiros foi um dos aspectos limitantes. As ações de PS têm sofrido restrições orçamentárias e sendo dependentes de iniciativas voluntárias para a viabilização de recursos. Outro fator limitante para o desenvolvimento das hortas nas UBS do município foi a falta de adesão de técnicos e profissionais da saúde da UBS, que não somente os ACS.

Foram colocados como desafios para a implementação das hortas, a capacitação de técnicos de saúde para a introdução dos fitoterápicos na UBS e a sensibilização dos médicos para que recomendem aos usuários a participação na atividade como parte da terapêutica.

Também foi identificada a necessidade de se incorporar a noção de processo e educação permanente junto aos profissionais de saúde e também usuários, a fim de mudar a prática predominante e definir melhor as formas de implantação, para que seja assumida mais efetivamente, intra e intersetorialmente no nível da gestão municipal.

Por fim, conclui-se que as atividades de cultivo nas hortas comunitárias mostram-se como práticas promotoras da saúde que integram elementos fundamentais das PIC.

Vale destacar que a abordagem da medicina integrativa busca a convivência de distintos paradigmas combinando vários aspectos como: a integração da medicina alternativa e complementar com a medicina convencional; a combinação de sistemas antigos de cura com a biomedicina moderna; a valorização do relacionamento médico-paciente e da comunicação; a consideração da pessoa de forma integral; a utilização de evidências e o enfoque na saúde, na cura e na prevenção de doenças ${ }^{13}$.

É necessário, portanto, aprofundar a investigação sobre a diversidade de estratégias de implantação de ações, alinhadas às práticas integrativas e complementares, dentre elas as hortas comunitárias e medicinais, de forma a efetivar o comprometimento do conjunto da gestão, em parceria com as associações locais, com ênfase na noção de território, deixando de ser uma responsabilidade exclusiva da saúde, para tornar-se uma política de governo. 


\section{Colaboradores}

CGA Costa e MT Garcia trabalharam na coleta de dados, interpretação dos dados, análise e redação do artigo. SM Ribeiro e CM Bógus trabalharam interpretação dos dados, análise e revisão final do texto. MFS Salandini trabalhou na coleta de dados, interpretação dos dados e revisão final do texto.

\section{Referências}

1. Santandreu A, Lovo IC. Panorama da agricultura urbana e periurbana no Brasil e diretrizes políticas para sua promoção. Belo Horizonte: Rede de Intercâmbio de Tecnologias Alternativas - REDE; 2007.

2. Coutinho MN. Agricultura Urbana: Análise e Reflexão Sobre os Marcos Legais e Normativos do Município de Belo Horizonte [monografia]. Belo Horizonte: Universidade Federal de Minas Gerais; 2007.

3. Machado AT, Machado CTT. Agricultura Urbana: Embrapa Cerrados. Planaltina: Embrapa; 2002.

4. Brasil. Ministério da Saúde (MS). Secretaria de Vigilância em Saúde. Secretaria de Atenção à Saúde. Política Nacional de Promoção da Saúde. 3a ed. Brasília: MS; 2010 .

5. Azevedo E, Pelicioni MCF, Westphal MF. Práticas intersetoriais nas políticas públicas de promoção de saúde. Physis [periódico na internet]. 2012 [acessado 2014 nov 11]; 22(4):1333-1356. Disponível em: http://www.scielo.br/scielo.php?script=sci_arttext\& pid=S0103-73312012000400005\&lng=en

6. Brasil. Ministério da Saúde (MS). Secretaria de Atenção à Saúde. Departamento de Atenção Básica. Política Nacional de Práticas Integrativas e Complementares no SUS. Brasília: MS; 2006.

7. Brasil. Ministério da Saúde (MS). Secretaria de Atenção à Saúde. Departamento de Atenção Básica. Relatório do $1^{o}$ seminário Internacional de Práticas Integrativas e Complementares em Saúde. Brasília: MS; 2009.

8. Minayo MCS. A utilização do método qualitativo para a avaliação de programas de saúde. In: Campos RO, Furtado J, Passos E, Benevides R, organizadores. Pesquisa Avaliativa em Saúde Mental - desenho participativo e efeitos da narratividade. Campinas: Hucitec; 2008. p. 27-37.

9. Minayo MCS. O desafio do conhecimento - Pesquisa Qualitativa em Saúde. 12a ed. São Paulo: Hucitec; 2010

10. Fernandez JCA, Sacardo DP. Abordagem qualitativa para avaliação de políticas públicas - implicações teóricas, éticas e políticas. In: Campos M, Cazzuni DH, organizadores. Avaliar para compreender - uma experiência na gestão de programa social com jovens em Osasco, SP. São Paulo: Hucitec; 2008. p. 59-95.

11. Deslandes SF. Concepções em pesquisa social: articulações com o campo da avaliação em serviços de saúde. Cad Saude Publica 1997; 13(1):103-107.

12. Tesser CD, Barros NF. Medicalização social e medicina alternativa e complementar - pluralização terapêutica do Sistema Único de Saúde. Rev Saude Publica 2008; 42(5):914-920.

\section{Agradecimentos}

À Fundação de Amparo à Pesquisa do Estado de São Paulo (FAPESP) pelos apoios financeiros recebidos no projeto intitulado de "Agricultura Urbana e Segurança Alimentar e Nutricional no Município de Embu das Artes".

13. Otani MAP, Barros NF. A Medicina Integrativa e construção de um novo modelo na saúde. Cien Saúde Colet 2011; 16(3):1801-1811.

14. Tesser CD. Práticas complementares, racionalidades médicas e promoção da saúde: contribuições poucos exploradas. Cad Saude Publica 2009; 25(8):1732-1742.

15. Souza EFAA, Luz MT. Bases socioculturais das práticas terapêuticas alternativas. Hist Cienc saude-Manguinhos 2009; 16(2):393-405.

16. Siegel P, Barros NF. Yoga e Saúde: o desafio da introdução de uma prática não-convencional no SUS [tese] Campinas: Universidade Estadual de Campinas; 2010.

17. Barros NF, Siegel P, Moura SM, Cavalari TA, Silva LG Furlanetti MR, Gonçalves AV. Yoga e promoção da saúde. Cien Saude Colet 2014; 19(4):1305-1314.

18. Silva EDC, Tesser CD. Experiência de pacientes com acupuntura no Sistema Único de Saúde em diferentes ambientes de cuidado e (des) medicalização social. Cad Saude Publica 2013; 29(11):2186-2196.

19. Cintra MER, Figueiredo R. Acupuntura e promoção da saúde: possibilidades no serviço público de saúde. Interface (Botucatu) 2010; 14(32):139-154.

20. Vaghetti HH, Padilha MICS, Carraro TE, Pires DEP, Santos VEP. Grupos sociais e o cuidado na trajetória humana. Rev Enferm UERJ 2007; 15(2):267-275.

21. Valla VV, Guimarães MB, Lacerda A. Religiosidade, Apoio Social e Cuidado Integral à Saúde - uma proposta de investigação voltada para as classes populares. In: Pinheiro R, Mattos RA, organizadores. Cuidado as fronteiras da integralidade. Rio de Janeiro: Hucitec, Abrasco; 2004. p. 103-117.

22. Santos BS. A crítica da razão indolente: contra o desperdício da experiência. $2^{a}$ ed. São Paulo: Cortez; 2000. World Health Organization. The 8th Global Conference

23. on Health Promotion; 2013 Jun 10-14; Helsinki, Finland. [acessado $2014 \mathrm{dez} 18$ ]. Available from: http:// www.who.int/healthpromotion/conferences/8gchp/ statement_2013/en/

24. Brasil. Ministério da Saúde (MS). Portaria nº 483, de de Abril de 2014. Redefine a Rede de Atenção à Saúde das Pessoas com Doenças Crônicas no âmbito do Sistema Único de Saúde (SUS) e estabelece diretrizes para a organização das suas linhas de cuidado. Diário Oficial da União 2014; 2 abr.

Artigo apresentado em 04/03/2015

Aprovado em 28/05/2015

Versão final apresentada em 30/05/2015 